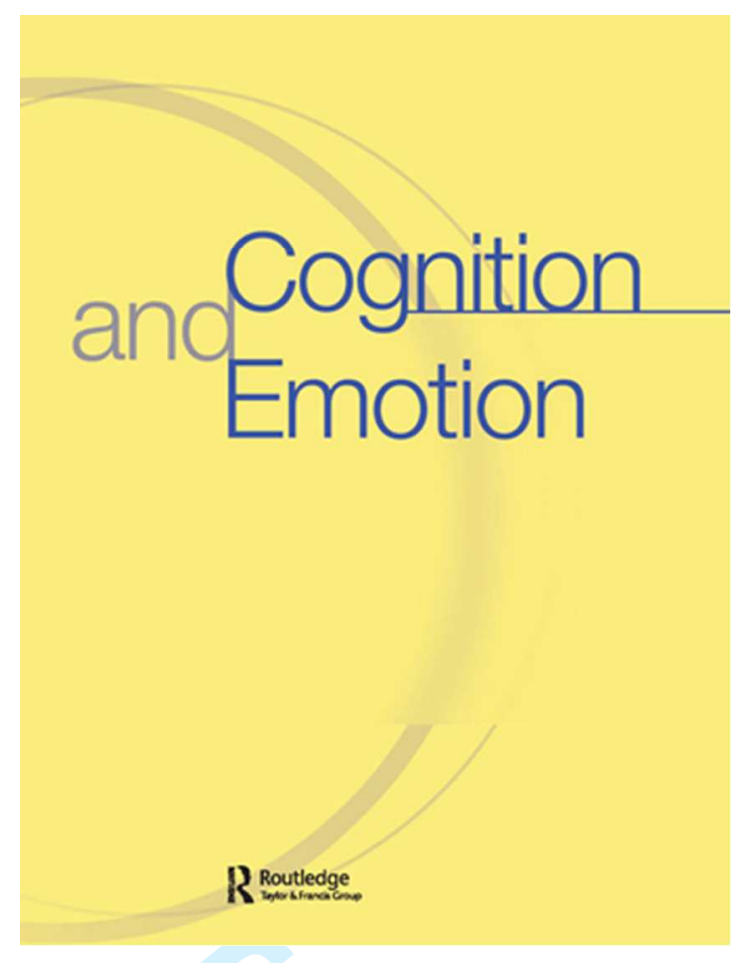

\title{
Bending rules: The shape of the perceptual generalization gradient is sensitive to inference rules
}

\begin{tabular}{|r|l|}
\hline Journal: & Cognition and Emotion \\
\hline Manuscript ID & CEM-FA 233.15.R3 \\
\hline Manuscript Type: & Full Article \\
\hline Date Submitted by the Author: & 07-Aug-2016 \\
\hline Complete List of Authors: & $\begin{array}{l}\text { Boddez, Yannick; KU Leuven } \\
\text { Bennett, Marc; KU Leuven; Trinity College Dublin } \\
\text { Van Esch, Silke; KU Leuven, } \\
\text { Beckers, Tom; KU Leuven; University of Amsterdam }\end{array}$ \\
\hline Keywords: & $\begin{array}{l}\text { associative learning, aversive learning, generalization, cognitive processes, } \\
\text { rule learning }\end{array}$ \\
\hline
\end{tabular}

\section{SCHOLARONE $^{\text {Ix }}$ \\ Manuscripts}

URL: http://mc.manuscriptcentral.com/pcem Email: pcem-peerreview@tandf.co.uk 
Bending rules: The shape of the perceptual generalization gradient is sensitive to inference rules Yannick Boddez ${ }^{1}$, Marc Patrick Bennett ${ }^{1,3}$, Silke van Esch ${ }^{1}$, and Tom Beckers ${ }^{1,2}$

${ }^{1} \mathrm{KU}$ Leuven, Belgium

${ }^{2}$ University of Amsterdam, the Netherlands

${ }^{3}$ Trinity College Dublin, Ireland

WORD COUNT: 5888

\begin{abstract}
Author Note
Yannick Boddez and Silke Van Esch, Faculty of Psychology and Educational Sciences, KU Leuven, Leuven, Belgium; Marc Patrick Bennett, Faculty of Psychology and Educational Sciences, KU Leuven, Leuven, Belgium, and Trinity College Dublin, Dublin, Ireland; Tom Beckers, Faculty of Psychology and Educational Sciences, KU Leuven, Leuven, Belgium, and Amsterdam Brain and Cognition Center and Department of Clinical Psychology, University of Amsterdam, Amsterdam, the Netherlands. This work was supported by the Belgian Science Policy Office under Grant P7/33 and by a KU Leuven Program Funding Grant PF/10/005.

Correspondence should be addressed to Yannick Boddez, Department of Psychology, KU Leuven, Tiensestraat 102 box 3712, 3000 Leuven, Belgium. E-mail: yannick.boddez@ppw.kuleuven.be. Tel: 003216325862.
\end{abstract}




\begin{abstract}
Generalizing what is learned about one stimulus to other but perceptually related stimuli is a basic behavioral phenomenon. We evaluated whether a rule learning mechanism may serve to explain such generalization. To this end, we assessed whether inference rules communicated through verbal instructions affect generalization. Expectancy ratings, but not valence ratings, proved sensitive to this manipulation. In addition to revealing a role for inference rules in generalization, our study has clinical implications as well. More specifically, we argue that targeting inference rules might prove to be an effective strategy to affect the excessive generalization that is often observed in psychopathology. Keywords: associative learning; aversive learning; generalization; cognitive processes; rule learning
\end{abstract}


Bending rules: The shape of the perceptual generalization gradient is sensitive to inference rules

A useful behavioral capacity shared by human and nonhuman animals alike is the ability to generalize on the basis of prior experiences. As a working definition, we propose to speak of a generalization effect when a stimulus elicits a response due to a learning experience in which that stimulus as such was not featured ${ }^{1}$. One might, for example, become careful around hot tea due to being burned by hot coffee. Importantly, our working definition of generalization is a functional definition that avoids a-priori assumptions about the mental mechanisms involved in generalization. Hence, these mechanisms remain open for investigation (De Houwer, 2011; De Houwer, Barnes-Homes, \& Moors, 2013; De Houwer \& Hughes, 2016). In the present study, we consider two candidate explanations, an association formation mechanism and a rule learning mechanism.

Laboratory research has revealed a characteristic of generalization that any good candidate explanation should be able to account for: Response strength systematically varies with the perceived similarity with the original learning experience (Ghirlanda \& Enquist, 2003). Consider a typical laboratory preparation in which a conditional stimulus (CS; say, a black square) is repeatedly paired with an unconditional stimulus (US; say, an electric shock), after which responding to a range of generalization stimuli that differ along a single perceptual dimension is tested (GSs; say, squares that vary through the shades of gray to white). Normally, an increase in perceptual distance between CS and GS goes together with a decrease in response strength. Placing the perceptual dimension on the $x$-axis and response strength on the $y$-axis, this results in a generalization gradient with a curvilinear shaped decrement of response strength (Ghirlanda \& Enquist, 2003).

Association formation theories explain the shape of this gradient by assuming that each stimulus is composed of multiple perceptual elements (darkness, presentation duration, loudness, etc.) that can each, to a certain degree, be associated with a mental representation of the US. Accordingly, GSs can activate the US representation to the extent that they are composed of elements that are also part of the CS (Bush \& Mosteller, 1951; McLaren \& Mackintosh, 2000; Pearce, 1987; Rescorla, 1976; Rescorla \& Furrow, 1977). Since stronger activation of the US representation is assumed to result in greater response strength, this principle elegantly explains the shape of the generalization gradient. Accordingly, this approach has become the dominant way to explain perceptual generalization effects at the mental level. 
Learning theorists have more recently investigated the extent to which, next to (or instead of) association formation principles, rule learning may provide an explanation of certain learning effects (De Houwer, 2014; McLaren et al., 2014; Mitchell, De Houwer, \& Lovibond, 2009). Although rule learning is common in humans (Maes et al., 2015), it is still unclear how such mechanism may account for phenomena like the perceptual generalization gradient. To obviate this lacuna, we theorize that people apply the inference rule "the more stimuli look alike, the higher the chance that they will have the same outcome". Generally speaking, an inference rule is a function to go from premises to a conclusion. In the case of perceptual generalization, people are assumed to make a judgment about the similarity between GS and CS and to infer from that similarity how likely it is that the GS will be followed by the same outcome as the CS. The rule "the more stimuli look alike, the higher the chance that they will have the same outcome" can explain the typical shape of the perceptual generalization gradient, because it has been demonstrated that subjects show stronger responding when they believe occurrence of a US to be more likely (Matute, Steegen, \& Vadillo, 2014).

Inference rules go beyond the scope of what association formation models can (be reasonably expected to) explain. These models simply lack a mechanism for accommodating the semantic structure of inference rules. Evidence for a role of inference rules in perceptual generalization would therefore motivate the development of a more complete theoretical framework (for a similar argument see Ahmed \& Lovibond, 2015a; Lovibond, 2003). Clinically this would be important as well, as it would suggest that targeting the rules people believe to be true might affect excessive fear generalization in patients suffering from anxiety and other disorders (Boddez, Baeyens, Hermans, Van der Oord, \& Beckers, 2013).

An established strategy to determine whether rules play a role in a certain learning phenomenon is to confirm or negate (parts of) the inference rule under investigation (e.g., through the use of verbal instructions). This manipulation should only affect the behavioral output if the inference rule is relevant for the learning phenomenon at hand (Mitchell and Lovibond, 2002). We used this strategy in the present study and assessed whether instructions that confirm or negate the generalization inference rule will affect the shape of the curvilinear generalization gradient.

Table 1 specifies the design and instructions used in the present experiment. Three groups completed simple Pavlovian conditioning, consisting of presentations of the CS with a shock US. Next, participants in the Rule-Confirmed Group received instructions that confirmed the rule that "the more 
stimuli look alike, the higher the chance that they will have the same outcome", while participants in the Rule-Negated Group received instructions that go against this rule. Afterwards, generalization was tested by presenting a series of GSs. A Control Group that did not receive specific instructions was included to verify whether a typical gradient could be obtained with the present training parameters. Shock expectancy ratings were collected, because evidence supports the validity of this measure (Boddez et al., 2013c). In addition to shock expectancy ratings, we also gathered valence ratings for the GSs.

We hypothesized that the generalization gradient in the Rule-Negated Group would differ from the gradient in the two other groups. Specifically, we predicted the Rule-Negated Group to produce an atypical generalization gradient whereby the rating values increase (rather than decrease) as the difference between GS and CS increases. In contrast, we expected the Rule-Confirmed and the Control Group to produce the typical generalization gradient. If the inference rule that we identified normally underlies generalization, negating said rule would require participants in the Rule-Negated Group to go against their already entertained beliefs. This might take more time than behaving in line with prior beliefs as required from participants in the Rule-Confirmed and Control Group. For exploratory reasons, we therefore measured the latency to perform expectancy and valence ratings (Craddock, Molet, \& Miller, 2012).

(Table 1 about here)

\section{Method}

\section{Participants}

Participants were recruited through an online experimental system where people see a list of experiments in which they can participate. This allowed us to attract both students and people from the community. Sixty-three participants $(M$ age $=25$ years, $S D=11$ years, age range: $19-51)$ took part in exchange for course credit or for financial reimbursement of $€ 8$. Participants were allocated in an alternating manner to the three groups until 21 participants were placed in each group (i.e., the first participant was placed in the first group, the second participant in the second group, the third participant in the third group, the fourth participant again in the first group, etc.). Sample size was based on previous studies (e.g., Ahmed \& Lovibond, 2015a). All participants provided informed 
consent and were aware that they could refrain from participating at any time. This study was approved by the standing ethical committee of the Faculty of Psychology and Educational Science. Due to the use of nociceptive stimulation, exclusion criteria were pregnancy, cardio-pulmonary difficulties, diagnosed psychiatric disorders or neurological conditions like epilepsy, and wrist pain. However, no volunteers met these criteria.

\section{Apparatus and stimuli}

Participants were tested in individual sessions on a Dell desktop computer with a screen that measured $54.6 \mathrm{~cm}$ wide by $49.3 \mathrm{~cm}$ tall. Five rectangles were employed $(9.53 \mathrm{~cm}$ wide $\times 7.99 \mathrm{~cm}$ high) - one black, one white and three that were different shades of grey. The stepwise differences in color were kept constant between consecutive stimuli on this color dimension. Either the black or white stimulus functioned as CS (completely counterbalanced) and the four remaining stimuli functioned as GSs.

The US was a 2 ms electrocutaneous stimulus administered to the left wrist and delivered by a Digitimer DS7A constant current stimulator (Hertfordshire, UK) through a pair of 11-mm Fukuda Standard Ag/AgCL electrodes filled with K-Y Jelly.

\section{Measures}

Shock expectancy ratings. Participants used a computer mouse to indicate their shock expectancy on a trial-by-trial basis. Expectancy was rated on an 11-point semi-continuous scale that went from 0 ("I am sure no electric stimulation will follow") over 5 ("I do not know") to 10 ("I am sure electric stimulation will follow"). The rating scale appeared at stimulus onset and stayed onscreen until participants selected a value.

Valence ratings. Valence was measured in the same way as the shock expectancy ratings, but the valence scale went from -5 (very unpleasant), over 0 (neutral) to 5 (very pleasant). Additional valence pre-ratings were collected before conditioning.

Reaction times. For each test trial, the time to make the rating was recorded (i.e., response latency). The reaction time was defined as the interval between the onset of the rating scale and the mouse click.

\section{Procedure}

Following general instructions and completion of the informed consent, participants completed a discrimination task. Participants were instructed to sort hard-copy prints of the CS and GSs according 
to color, from light to dark, or vice versa (counterbalanced). This was done to introduce participants to the stimulus dimension and to test for their visual acuity (all participants did this task faultlessly). Subsequently, electrodes were attached to the wrist and the intensity of the electric shock was individually set for each participant at a level described as "unpleasant and demanding some effort to tolerate, but not necessarily painful". It is of note that the mean shock intensity in this study was 16.67 $\mathrm{mA}(S D=7.34)$.

Experimental instructions then appeared on the computer screen and were orally reiterated by the experimenter. These general instructions stated that images would appear on the computer screen and that an electric shock could follow some of the images. The use of the rating scales was explained as well. Following this, participants were presented with all stimuli and asked to judge their valence on a rating scale (i.e., valence pre-ratings).

Then the actual contingency training started. All participants underwent simple conditioning training consisting of five presentations of the CS followed by a shock US. Participants indicated their expectancy of the US on every conditioning trial. Following conditioning, participants received the crucial instructions. Participants in all three groups were instructed that, once again, images would appear that could be followed by electric shock. Importantly, participants in the Rule-Confirmed Group were also instructed that "(1) The more an image looks like the image that was followed by electric shock, the higher the chances that this image will be followed by electric shock as well", and "(2) The less an image looks like the image that was followed by electric shock, the lower the chances that this image will be followed by electric shock as well". On the other hand, participants in the Rule-Negated Group were also instructed that "(1) The more an image looks like the image that was followed by electric shock, the lower the chances that this image will be followed by electric shock as well", and "(2) The less an image looks like the image that was followed by electric shock, the higher the chances that this image will be followed by electric shock as well". Participants in the Control Group did not receive additional instructions.

In one generalization test phase, participants were asked for their shock expectancy and in another generalization test phase participants were asked for valence ratings (counterbalanced order). In both test phases, the CS and 4 GSs were presented once in randomized order and without shock, after which the experiment ended. 
All intertrial intervals were $6000 \mathrm{~ms}$ and stimuli were presented for as long as it took the participants to make their ratings. The rating scale appeared and disappeared together with the stimuli. Shocks were delivered immediately after stimulus offset. The assignment of either the black or white square as CS was completely counterbalanced. Stimulus sequence, stimulus presentation and response generation were controlled by Affect 4.0 computer software (Spruyt, Clarysse, Vansteenwegen, Baeyens, \& Hermans, 2010).

\section{Results}

We will describe the split-plot factorial design at the beginning of each data section. GreenhouseGeisser corrections were applied where necessary.

\section{Acquisition: Shock expectancy}

Figure 1 depicts shock expectancy ratings by Group for the five acquisition trials. Visual inspection suggests an increase in shock expectancy over trials in all groups. A 3 (Group: Rule-Confirmed, RuleNegated, Control) $\times 5$ (Trial: $1-5)$ repeated-measures ANOVA indeed revealed a main effect of Trial, $F(2.78,166.79)=45.13, M S E=4.31, p<0.001, \eta^{2} p=.43$, but not of Group, $F(2,60)=2.27, M S E=$ 12.87, $\eta^{2} p=.07$. The Group $\times$ Trial interaction was not significant either, $F(5.56,166.79)<1, M S E=$ 4.31, $\eta^{2} p=.02$, which was expected since groups received similar treatment until this point. No valence data were collected during acquisition training.

(Figure 1 about here)

\section{Test: Shock expectancy}

Figure 2 shows the generalization of shock expectancy, sorted by Group. Visual inspection suggests that the generalization gradient in the Rule-Confirmed Group is similar to the pattern in the Control Group, but opposite to the pattern in the Rule-Negated Group. This was confirmed by a 3 (Group: Rule-Confirmed, Rule-Negated, Control) × 5 (Stimulus Type: CS, GS1, GS2, GS3, GS4) repeatedmeasures ANOVA, which revealed a significant Group * Stimulus Type interaction, $F(5.39,161.65)=$ 12.95, MSE $=7.91, p<0.001, \eta^{2} p=.30$. The analysis further revealed the presence of an effect of Stimulus, $F(2.69,161.65)=4.43, M S E=7.91, p<0.01, \eta^{2} p=.07$, and the absence of an effect of Group, $F(2,60)<1, M S E=6.30, \eta^{2} p=.03$. Follow-up interaction tests showed that the effect of stimulus differed between the Rule-Negated and the Control Group, $F(2.78,111.38)=14.36, M S E=$ 
(Figure 3 about here)

\section{Test: Reaction times}

Figures 4 and 5 show the response latencies for respectively the shock expectancy ratings and for the valence ratings during test. With respect to the shock expectancy ratings, a 3 (Group: Rule-Confirmed, Rule-Negated, Control) × 5 (Stimulus Type: CS, GS1, GS2, GS3, GS4) repeated-measures ANOVA revealed the presence of a Group effect, $F(2,60)=3.61, M S E=4431235.34, p<0.05, \eta^{2} p=.11$. As can be seen in Figure 4, people in the Rule-Negated Group were slower relative to the other groups. The analysis further revealed a main effect of Stimulus, $F(4,240)=2.82, M S E=1653026.19, p<$ $0.05, \eta^{2} p=.04$, but no Stimulus Type * Group interaction, $F(8,240)=1.03, M S E=1653026.19, \eta^{2} p=$ .03.

With respect to response latencies for valence ratings, depicted in Figure 5, the repeatedmeasures ANOVA revealed no main effects of Group and Stimulus, both Fs < 1, MSE's $=9502498.25$ 
and 2993972.5 respectively, and both $\eta^{2} p=.02$, but a significant Group * Stimulus Type interaction, $F(8,240)=2, M S E=2993972.5, p<0.05, \eta^{2} p=.06$.

(Figures 4 and 5 about here)

\begin{abstract}
Discussion
If we want to understand generalization, it is important to understand the factors that influence it. The present study demonstrates that generalization gradients in shock expectancy are sensitive to inference rules communicated through verbal instructions. The perceptual generalization gradient was completely reversed in the Rule-Negated Group. These results are compatible with the assumption that inference rules may govern the shape of perceptual generalization gradients. If the rule that we identified ("the more stimuli look alike, the higher the chance that they will have the same outcome") would have been irrelevant with respect to generalization, our manipulation should not have had any effect.
\end{abstract}

Vervliet, Kindt, Vansteenwegen, and Hermans (2010) and Ahmed and Lovibond (2015b) previously reported that generalization towards specific stimulus features occurs in a way that is consistent with participants' beliefs. They tested generalization of fear responding to GSs that shared either color or shape with the CS. Crucially, participants were instructed either that "color of the CS" or "shape of the CS" would be predictive of shock. Generalization was stronger to the stimulus containing the instructed feature, suggesting that instructions impacted generalization of fear. Our results are in line with this finding and extend it to the whole generalization gradient. That is, our results not only show that beliefs may affect generalization (as demonstrated in the studies of Vervliet et al., 2015, and of Ahmed \& Lovibond, 2015), but in addition show that the belief in the rule we identified may provide an explanation for the typical shape of the perceptual generalization gradient.

A unique feature of the current study, relative to previous research, is that we also included a reaction time measure and valence ratings. Our finding that people were slower to report their shock expectancy in the Rule-Negated Group can be interpreted in different ways. One possibility is that people had to go against their usual beliefs in this condition, which would be in line with our hypothesis that the inference rule at hand normally underlies generalization. However, other theoretical possibilities exist. One might, for example, also argue that the delay is caused by the time needed to 
override representations activated by an association formation system, which would be more in line with a dual-process account (e.g., McLaren et al., 2014).

Interestingly, the valence data show a different pattern than the shock expectancy data. The instructions did not affect the generalization gradient in valence ratings and there was no main effect of Group in response latency. Participants in all groups rated the CS as most negative, with gradually more positive ratings towards generalization stimuli that differ more from the CS. Although surprising at first glance, there are other demonstrations of valence conditioning effects going counter to participants' beliefs (Baeyens, Vansteenwegen, \& Hermans, 2009). Common examples include situations in which US occurrence is correctly believed to be modulated, but acquired (dis)liking is not (Baeyens, Crombez, De Houwer, \& Eelen, 1996; Baeyens, Henrickx, Crombez, \& Hermans, 1998), and situations in which US occurrence is no longer expected due to extinction training, but conditional (dis)liking nonetheless persists (Vansteenwegen, Francken, Vervliet, De Clercq, \& Eelen, 2006). A recent study also found that acquired valence (but not physiological responses including fear potentiated startle) resists instructed extinction (Luck \& Lipp, 2015). The observation that results were different for the shock expectancy and valence ratings may suggest that different mechanisms are involved, with generalization of valence conditioning being better explained by traditional association formation theories and falling out of scope of the rule learning mechanism (for a similar argument see Baeyens et al., 2009). However, another possibility that should be considered is that the valence ratings are mediated by a different rule than the one that we manipulated. An obvious challenge for future research would be to identify that rule and manipulate it to observe its effect on valence conditioning.

At least three procedural matters deserve comment. First, we did not include a stimulus not paired with shock during acquisition training. A comparison of the CS followed by shock with such control stimulus would have provided an index of the acquisition effect, while controlling for nonspecific sensitization effects. We decided to not include this control stimulus during acquisition, because rather than remaining neutral, it can become a signal for the absence of the US (i.e., a differential inhibitor; Boddez et al., 2013a) and, as such, can affect the shape of the generalization gradient in an unwanted way. The response to generalization stimuli is then not only determined by their similarity to the stimulus signaling the US, but also by their similarity to the stimulus signaling the absence of the US (Ghirlanda \& Enquist, 2003). Because of this reason, animal researchers often use 
generalization procedures that do not include a control stimulus not paired with the US, just like we did not include such stimulus in this study (for a review see Ghirlanda \& Enquist, 2003). It should, however, be noted that there are also limitations of not including this control stimulus not paired with shock during acquisition. First, the verbal instructions we gave (See Table 1) only spoke on the similarity between the test stimuli and "the image that was followed by electric shock", so it is not clear what the effect of this instruction would be in a procedure where the generalization test stimuli additionally share a degree of similarity with a stimulus not followed by shock. Second, the lack of control for non-specific sensitization might also cloud the interpretation of the generalization data. Along the perceptual continuum, the test stimuli not only become increasingly different from the stimulus that signaled shock, but also become increasingly novel. One could therefore argue that the differences in responding to the generalization stimuli are merely due to differences in novelty. Although the latter might be considered a problem, the typical shape of a generalization gradient (see, for example, the shape of the gradient in the Control Group in Figure 1) would seem to go against that interpretation, because one would have to assume that weaker novelty responses are seen to stimuli that are more novel (i.e., to the stimuli that are more different from the stimulus signaling shock). This appears counterintuitive, as one would expect a stronger novelty response to more novel stimuli. Still, follow-up research should include this type of control stimulus to thoroughly evaluate its effects and to make sure that it does not change our present conclusions.

A second procedural matter that deserves comment is that the present study relied, to an important extent, on self-report measures. A recent review concluded that trial-by-trial shock expectancy ratings provide a robust measure of learning and stand the litmus test of external validity with respect to anxiety disorders (Boddez et al., 2013c). However, some researchers argue that caution is warranted when using self-report measures, because they might be susceptible to effects of social desirability and experimental demand (e.g., Craske, Hermans, \& Vansteenwegen, 2006). It would therefore be useful to include more indirect (e.g., physiological) measures in future research. One should, however, keep in mind that complex learning situations can complicate the use of physiological measures, as these measures are not always sensitive enough to pick up subtle differences between multiple stimuli (e.g., Ahmed \& Lobivond, 2015b; Chan \& Lovibond, 1996). In addition, measuring physiology requires the use of a fixed time window for stimulus presentation and responding, which we could not implement in this study because we recorded reaction times until 
participants made their rating. Future studies that make use of indirect measures should include workarounds for these issues.

A third procedural matter that deserves comment is that the crucial instructional manipulation was given after acquisition training. This allowed controlling for the impact of instructions on initial learning and can be considered a strength of the present design (for an extensive discussion see Ahmed \& Lovibond, 2015b).

Excessive generalization is a core feature of pathological fear (e.g., Dymond et al., 2014; Lenaert et al.; 2014; Lissek et al., 2005; Lissek et al., 2010). A war veteran suffering from posttraumatic stress disorder might, for example, respond fearfully to fireworks that sound like a nearly fatal gunshot from his past (Boddez, Baeyens, Hermans, \& Beckers, 2013; Dymond, Dunsmoor, Vervliet, Roche, \& Hermans, 2015). Insight into the factors that influence generalization can enhance our understanding of anxiety disorders and inspire new ways of treatment and prevention. Our results demonstrate that providing verbal information can affect generalization. Since the treatment of generalized fear through traditional exposure therapy is often difficult (Boddez et al., 2012; Vervliet, Vansteenwegen, Baeyens, Hermans, \& Eelen, 2005; Vervoort, Vervliet, Bennett, \& Baeyens, 2014), interventions that target inference rules may provide for efficient and cost-effective ways of reducing anxiety. As of now, it is however not guaranteed that the use of instructions will be as effective in a clinical sample. Further research might focus on the exact boundary conditions needed to affect generalization.

With respect to future research, it is important to note that, in addition to perceptually related stimuli, generalization sometimes involves symbolically related stimuli. For example, in blood-injection phobia, stimuli as perceptually diverse as the sight of a needle, walking in a hospital corridor, or even watching a surgery television show can elicit strong fear responding (Dunsmoor \& Murphy, 2015; Dymond et al., 2014). As another step toward a more complete theoretical framework, future studies could try to identify and manipulate the rules that play a role in such non-perceptual generalization (for conceptually related work see Dymond, Roche, Forsyth, Whelan, \& Rhoden, 2007; 2008). This could lead to a unified model of perceptual and symbolic generalization.

In summary, the typical shape of the perceptual generalization gradient has traditionally been explained in terms of associative connections originating from stimulus elements common to the conditional and generalization stimuli. We highlighted the role of inference rules in this fundamental 
learning phenomenon. Specifically, shock expectancy, but not valence, results provide evidence for the alternative, or additional, explanation that inference rules (sometimes) underlie the shape of the perceptual generalization gradient. 


\section{References}

Ahmed, O., \& Lovibond, P. F. (2015a). The impact of previously learned feature-relevance on generalisation of conditioned fear in humans. Journal of Behavior Therapy and Experimental Psychiatry, 46, 59-65.

Ahmed, O., \& Lovibond, P. F. (2015b). The impact of instructions on generalization of conditioned fear in humans. Behavior therapy, 46, 597-603.

Baeyens, F., Crombez, G., De Houwer, J., \& Eelen, P. (1996). No evidence for modulation of evaluative flavor-flavor associations in humans. Learning and Motivation, 27, 200-241.

Baeyens, F., Hendrickx, H., Crombez, G., \& Hermans, D. (1998). Neither extended sequential nor simultaneous feature positive training result in modulation of evaluative flavor conditioning in humans. Appetite, 31, 185-204.

Baeyens, F., Vansteenwegen, D., \& Hermans, D. (2009). Associative learning requires associations, not propositions. Behavioral and Brain Sciences, 32, 198-199.

Boddez, Y., Callaerts-Vegh, Z., Vervliet, B., Baeyens, F., D'Hooge, R., Hermans, D., \& Beckers, T. (2012). Stimulus generalization and return of fear in C57BL/6J mice. Frontiers in Behavioral Neuroscience, 6, art. nr. 41.

Boddez, Y., Baeyens, F., Hermans, D., \& Beckers, T. (2013a). A learning theory approach to anxiety disorders: Human fear conditioning and the added value of complex acquisition procedures. In: Emmelkamp P., Ehring T. (Eds.), International Handbook of Anxiety Disorders: Theory, Research and Practice. London: Wiley-Blackwell.

Boddez, Y., Baeyens, F., Hermans, D., Van der Oord, S., \& Beckers, T. (2013b). Increasing the selectivity of threat through post-training instructions: Identifying one stimulus as source of danger reduces the threat value of surrounding stimuli. Journal of Experimental Psychopathology, 4, 315-324.

Boddez, Y., Baeyens, F., Luyten, L., Vansteenwegen, D., Hermans, D., \& Beckers, T. (2013c). Rating data are underrated: Validity of US expectancy in human fear conditioning. Journal of Behavior Therapy and Experimental Psychiatry, 44, 201-206.

Bush, R. R., \& Mosteller, F. (1951). A model for stimulus generalization and discrimination. Psychological Review, 58, 413-423.

Chan, C. K., \& Lovibond, P. F. (1996). Expectancy bias in trait anxiety. Journal of Abnormal 
Psychology, 105, 637-647.

Craddock, P., Molet, M., \& Miller, R. R. (2012). Reaction time as a measure of human associative learning. Behavioural processes, 90, 189-197.

Craske, M. G., Hermans, D., \& Vansteenwegen, D. (2006). Fear and Learning: From Basic Processes to Clinical Implications. American Psychological Association, Washington, DC.

De Houwer, J. (2011). Why the cognitive approach in psychology would profit from a functional approach and vice versa. Perspectives on Psychological Science, 6, 202-209.

De Houwer, J. (2014). Why a propositional single-process model of associative learning deserves to be defended. In J. W. Sherman, B. Gawronski, \& Y. Trope (Eds.), Dual Processes in Social Psychology. NY: Guilford.

De Houwer, J., Barnes-Holmes, D., \& Moors, A. (2013). What is learning? On the nature and merits of a functional definition of learning. Psychonomic bulletin \& review, 20, 631-642.

De Houwer, J., \& Hughes, S. (2016). Environmental Regularities as a Concept for Carving up the Realm of Learning Research: Implications for Relational Frame Theory. Journal of Contextual Behavioral Science. Advance online publication.

Dunsmoor, J. E., \& Murphy, G. L. (2015). Categories, concepts, and conditioning: how humans generalize fear. Trends in cognitive sciences, 19, 73-77.

Dymond, S., Dunsmoor, J. E., Vervliet, B., Roche, B., \& Hermans, D. (2015). Fear generalization in humans: Systematic review and implications for anxiety disorder research. Behavior therapy, $46,561-582$.

Dymond, S., Roche, B., Forsyth, J. P., Whelan, R., \& Rhoden, J. (2007). Transformation of avoidance response functions in accordance with the relational frames of same and opposite. Journal of the Experimental Analysis of Behavior, 88, 249-262.

Dymond, S., Roche, B., Forsyth, J. P., Whelan, R., \& Rhoden, J. (2008). Derived avoidance learning: Transformation of avoidance response functions in accordance with the relational frames of same and opposite. The Psychological Record, 58, 271-288.

Ghirlanda, S., \& Enquist, M. (2003). A century of generalization. Animal Behaviour, 66, 15-36.

Lenaert, B., Boddez, Y., Griffith, J. W., Vervliet, B., Schruers, K., \& Hermans, D. (2014). Aversive learning and generalization predict subclinical levels of anxiety: A six-month longitudinal study. Journal of anxiety disorders, 28, 747-753. 
Lissek, S., Powers, A. S., McClure, E. B., Phelps, E. A., Woldehawariat, G., Grillon, C., et al. (2005). Classical fear conditioning in the anxiety disorders: A meta-analysis. Behaviour Research and Therapy, 43, 1391-1424.

Lissek, S., Rabin, S., Heller, R., Lukenbaugh, D., Geraci, M., Pine, D., et al. (2010). Overgeneralization of conditioned fear as a pathogenic marker of panic disorder. American Journal of Psychiatry, 167, 47-55.

Lovibond, P. F. (2003). Causal beliefs and conditioned responses: retrospective revaluation induced by experience and by instruction. Journal of Experimental Psychology: Learning, Memory, and Cognition, 29, 97.

Luck, C. C., \& Lipp, O. V. (2015). A potential pathway to the relapse of fear? Conditioned negative stimulus evaluation (but not physiological responses) resists instructed extinction. Behaviour research and therapy, 66, 18-31.

Maes, E., De Filippo, G., Inkster, A. B., Lea, S. E., De Houwer, J., D’Hooge, R., Beckers, T., \& Wills, A. J. (2015). Feature-versus rule-based generalization in rats, pigeons and humans. Animal cognition, 18, 1267-1284.

Matute, H., Steegen, S., \& Vadillo, M. A. (2014). Outcome probability modulates anticipatory behavior to signals that are equally reliable. Adaptive behavior, 22, 207-216.

McLaren, I. P., Forrest, C. L. D., McLaren, R. P., Jones, F. W., Aitken, M. R. F., \& Mackintosh, N. J. (2014). Associations and propositions: The case for a dual-process account of learning in humans. Neurobiology of learning and memory, 108, 185-195.

McLaren, I. P. L., \& Mackintosh, N. J. (2000). An elemental model of associative learning: I. Latent inhibition and perceptual learning. Animal Learning \& Behavior, 28, 211-246.

Mitchell, C. J., De Houwer, J., \& Lovibond, P. F. (2009). The propositional nature of human associative learning. Behavioral and Brain Sciences, 32, 183-198.

Mitchell, C. J., \& Lovibond, P. F. (2002). Backward and forward blocking in human electrodermal conditioning: Blocking requires an assumption of outcome additivity. The Quarterly Journal of Experimental Psychology: Section B, 55, 311-329.

Pearce, J. M. (1987). A model for stimulus-generalization in Pavlovian conditioning. Psychological Review, 94, 61-73.

Rescorla, R. A. (1976). Stimulus generalization: Some predictions from a model of Pavlovian 
conditioning. Journal of Experimental Psychology: Animal Behavior Processes, 2, 88-96.

Rescorla, R. A., \& Furrow, D. R. (1977). Stimulus similarity as a determinant of Pavlovian conditioning. Journal of Experimental Psychology: Animal Behavior Processes, 3, 203-215.

Spruyt, A., Clarysse, J., Vansteenwegen, D., Baeyens, F., \& Hermans, D. (2010). Affect 4.0: A free software package for implementing psychological and psychophysiological experiments. Experimental Psychology, 57, 36-45.

Vansteenwegen, D., Francken, G., Vervliet, B., De Clercq, A., \& Eelen, P. (2006). Resistance to extinction in evaluative conditioning. Journal of Experimental Psychology: Animal Behavior Processes, 32, 71-79.

Vervliet, B., Kindt, M., Vansteenwegen, D., \& Hermans, D. (2010). Fear generalization in humans: Impact of verbal instructions. Behaviour Research and Therapy, 48, 38-43.

Vervliet, B., Vansteenwegen, D., Baeyens, F., Hermans, D., \& Eelen, P. (2005). Return of fear in a human differential conditioning paradigm caused by a stimulus change after extinction. Behaviour Research and Therapy, 43, 357-371.

Vervoort, E., Vervliet, B., Bennett, M., \& Baeyens, F. (2014). Generalization of human fear acquisition and extinction within a novel arbitrary stimulus category. PLoS One, 9, art. nr. 10.1371/journal.pone.0096569, e96569. 


\section{Footnotes}

${ }^{1}$ That is, we define generalization effects as a subset of learning effects, which are themselves defined as changes in behavior that result from regularities in the environment (for an extensive discussion see De Houwer, Barnes-Homes, \& Moors, 2013). More specifically, we therefore define a generalization effect as a change in behavior due to regularities in the environment in which the generalization stimulus (i.e., the antecedent or test stimulus) was not featured. 
Table 1

Design summary

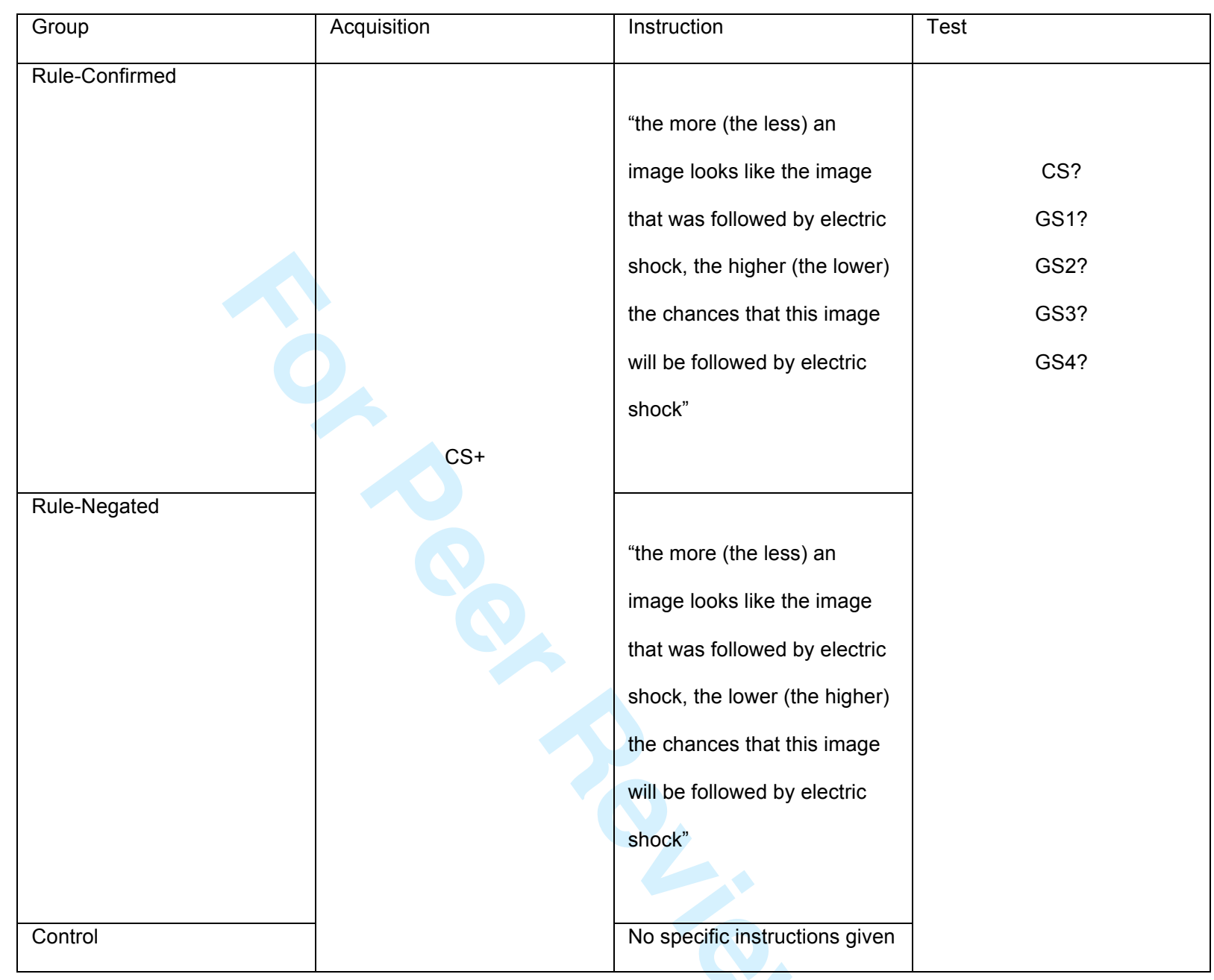


Figure 1. Mean shock expectancy ratings during acquisition. Vertical bars denote 0.95 confidence intervals.

Figure 2. Mean shock expectancy ratings at testing. Vertical bars denote 0.95 confidence intervals.

Figure 3. Valence ratings at testing. Vertical bars denote 0.95 confidence intervals.

Figure 4. Reponse latencies for the shock expectancy ratings during test. Vertical bars denote 0.95 confidence intervals.

Figure 5. Reponse latencies for the valence ratings during test. Vertical bars denote 0.95 confidence intervals. 


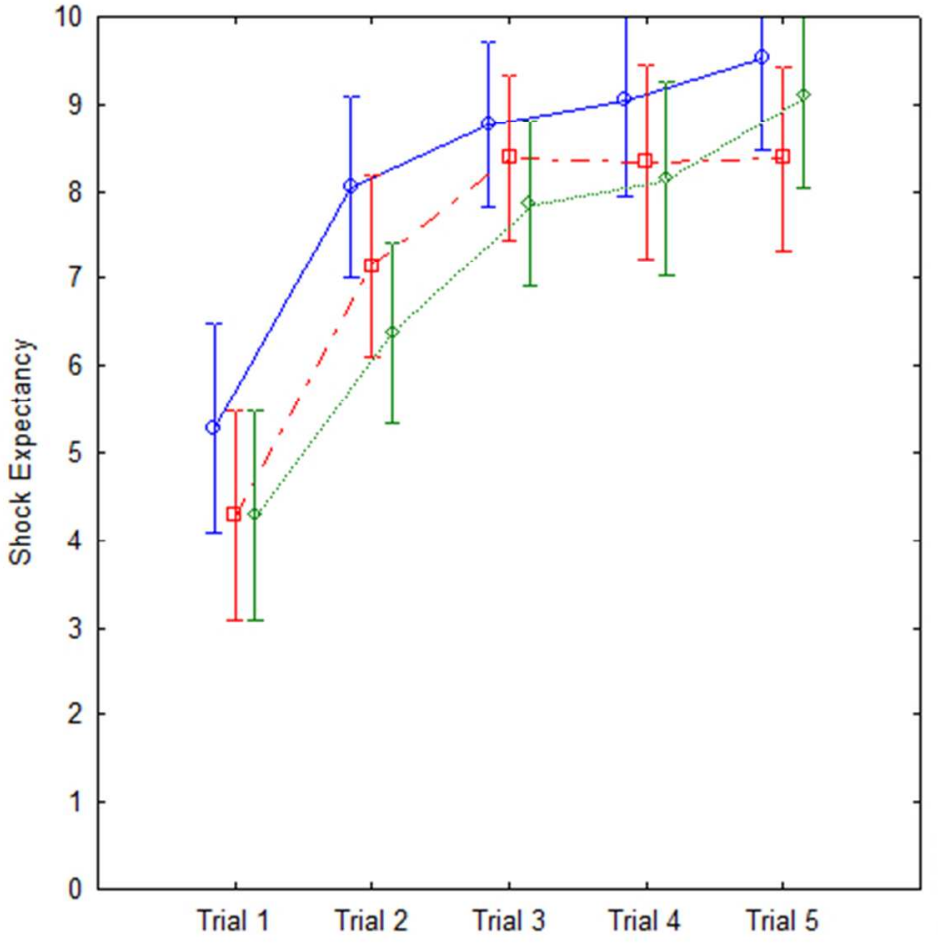

I Rule-Confirmed Group Rule-Negated Group क. Control Group

Figure 1. Mean shock expectancy ratings during acquisition. Vertical bars denote 0.95 confidence intervals. $165 \times 123 \mathrm{~mm}(96 \times 96 \mathrm{DPI})$ 
1

2

3

4

5

6

7

8

10

11

12

13
14

15

16

17

18

19

20

21

22

23

24

25

26

27

28

29

30

31

32

33

34

35

36

37

38

39

40

41

42

43

44

45

46

47

48

49

50

51

52

53

54

55

56

57

58

59

60

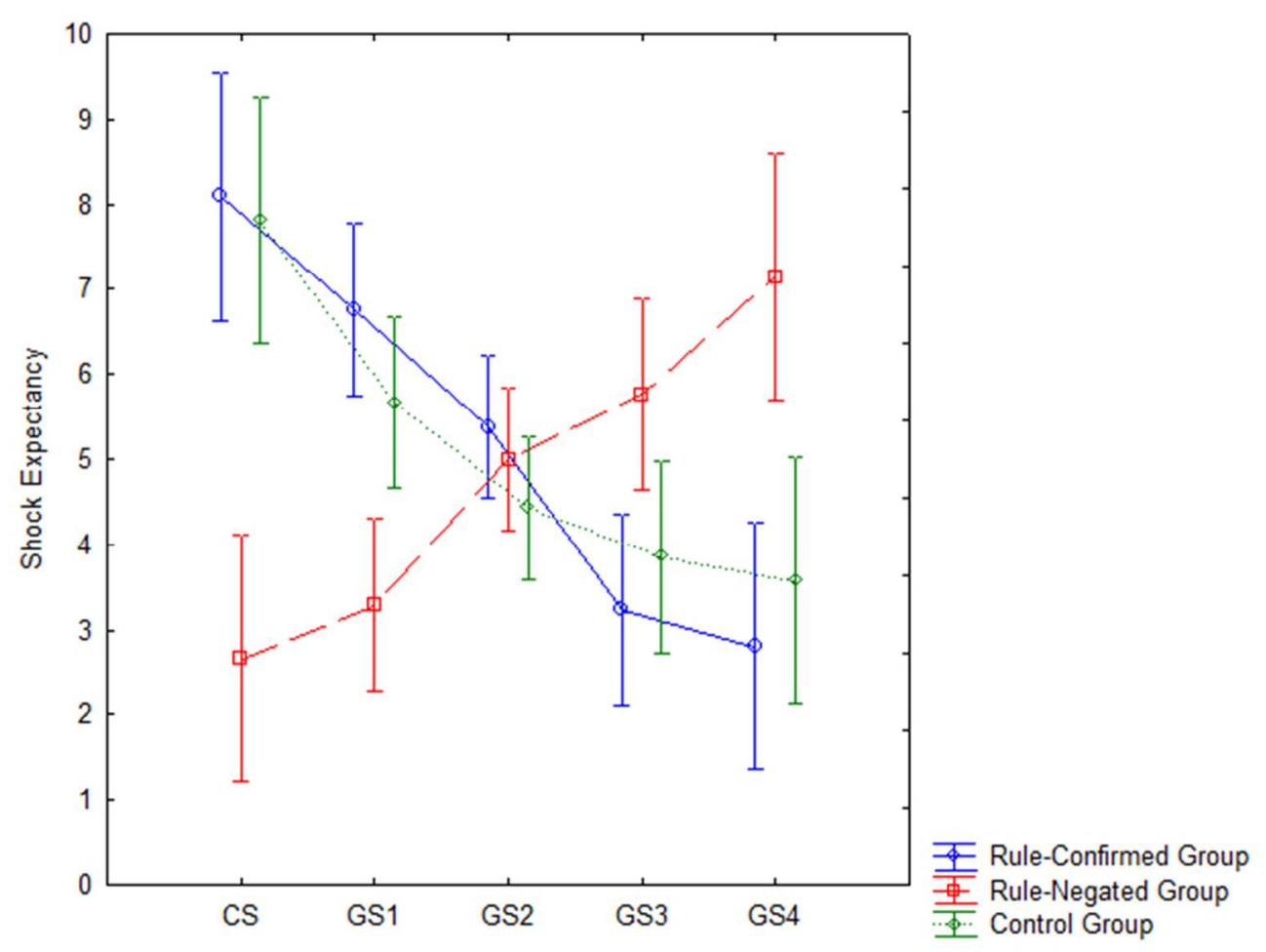

Figure 2. Mean shock expectancy ratings at testing. Vertical bars denote 0.95 confidence intervals. $165 \times 123 \mathrm{~mm}(96 \times 96 \mathrm{DPI})$ 


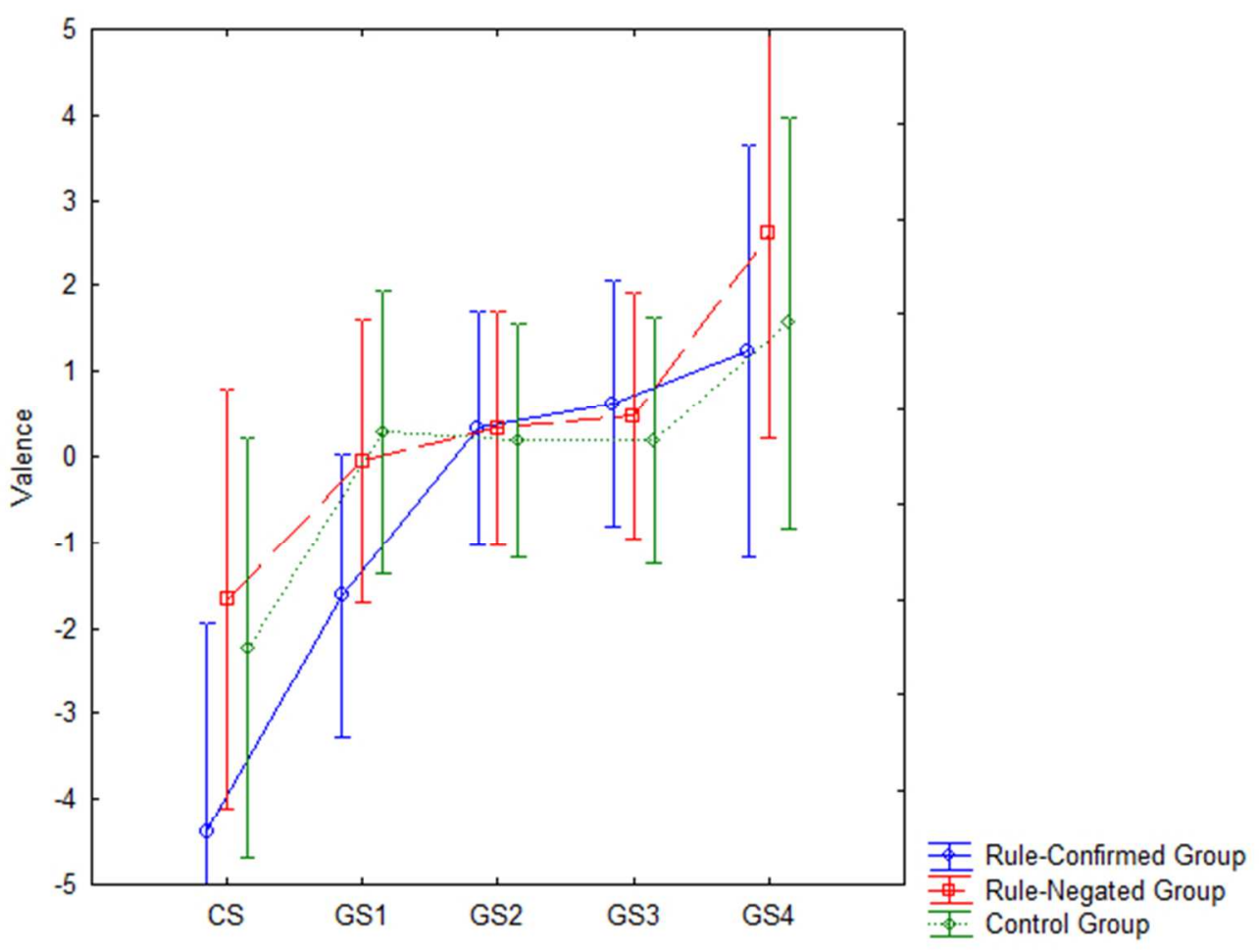

Figure 3. Valence ratings at testing. Vertical bars denote 0.95 confidence intervals. $165 \times 123 \mathrm{~mm}(96 \times 96 \mathrm{DPI})$

URL: http://mc.manuscriptcentral.com/pcem Email: pcem-peerreview@tandf.co.uk 
1

2

3

4

5

6

7

8

10

10

11

12

13

14

15

16

17

18

19

20

21

22

23

24

25

26

27

28

29

30

31

32

33

34

35

36

37

38

39

40

41

42

43

44

45

46

47

48

49

50

51

52

53

54

55

56

57

58

59

60

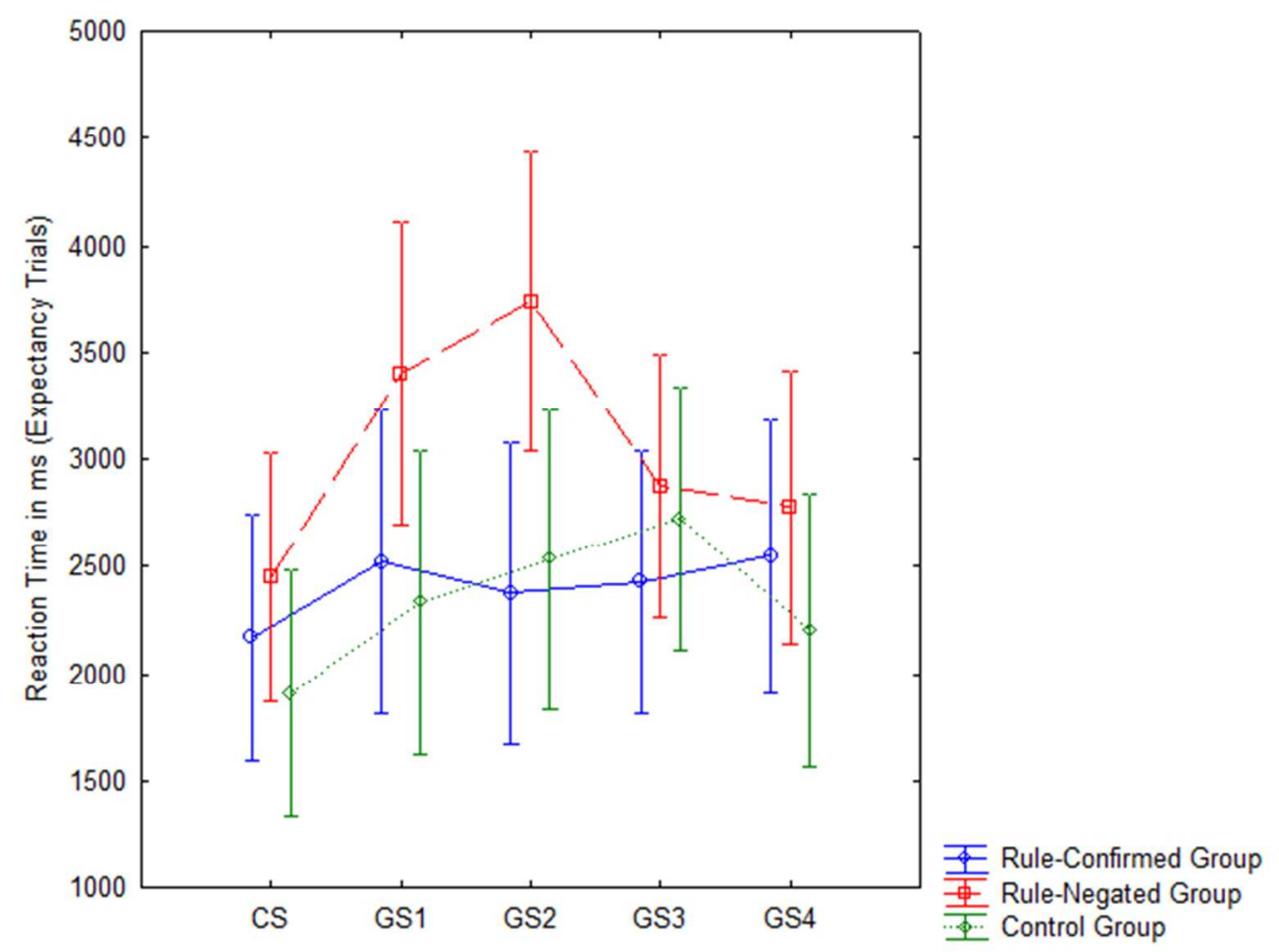

Figure 4. Reponse latencies for the shock expectancy ratings during test. Vertical bars denote 0.95 confidence intervals.

$165 \times 123 \mathrm{~mm}$ (96 x 96 DPI) 


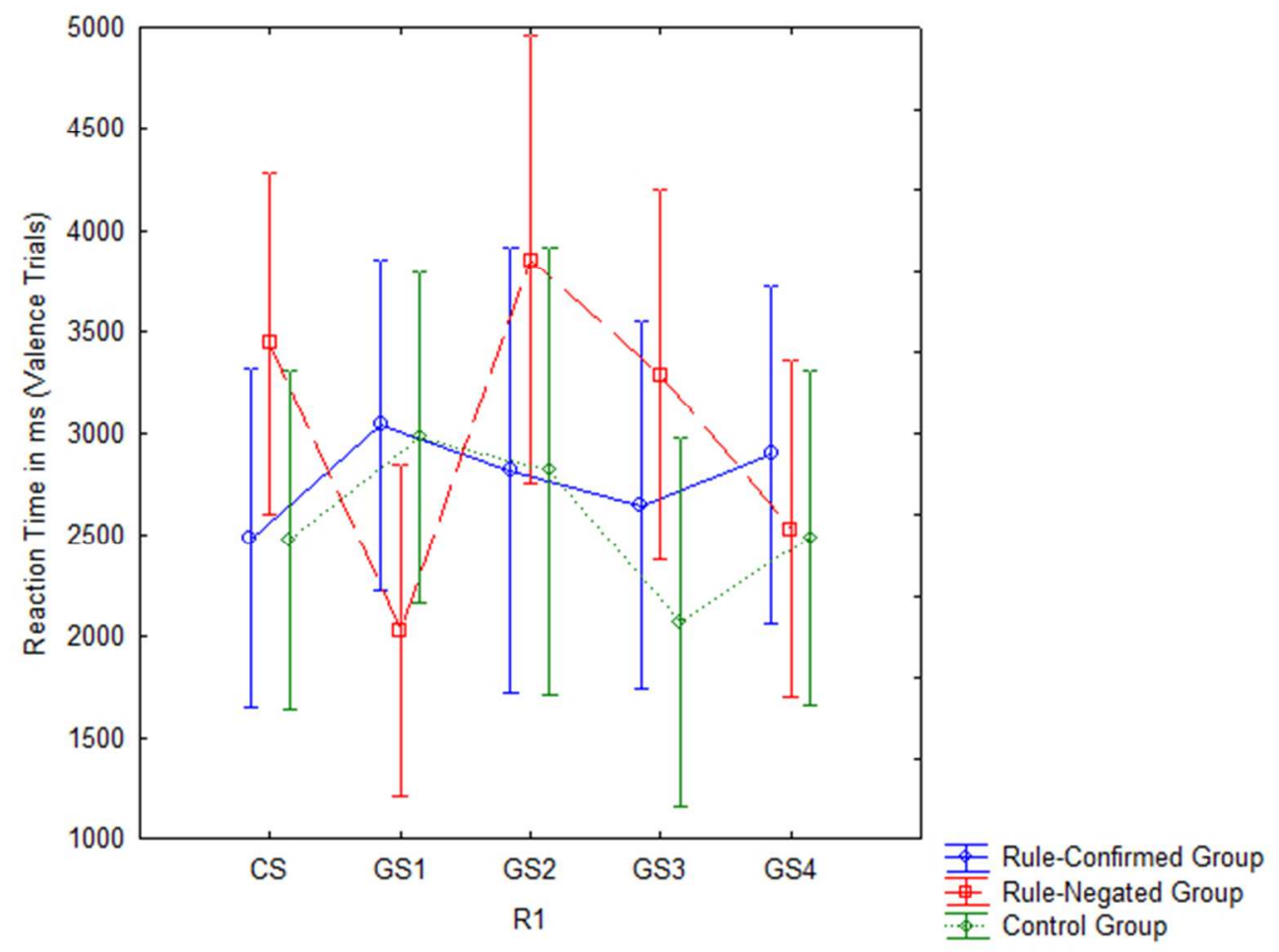

Figure 5. Reponse latencies for the valence ratings during test. Vertical bars denote 0.95 confidence intervals.

$165 \times 123 \mathrm{~mm}(96 \times 96 \mathrm{DPI})$

36

37

38

39

40

41

42

43

44

45

46

47

48

49

50

51

52

53

54

55

56

57

58

59

60

URL: http://mc.manuscriptcentral.com/pcem Email: pcem-peerreview@tandf.co.uk 